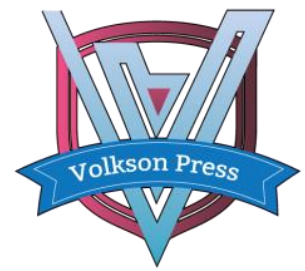

\title{
DIFFERENTIAL SCANNING CALORIMETRY ANALYSIS, EQUILIBRIUM SOLUTION AND LIPID-WATER PARTITION COEFFICIENT OF 0-19, A PROMISING PRODRUG CANDIDATE OF O-DESMETHYLVENLAFAXINE
}

\author{
Zihao Zhang, Guiyong Wang, Zhongyu Zhang, Yang Zhang* \\ School of Chemistry and Pharmaceutical Engineering, Jilin Institute of Chemical Technology, Jilin 132022, China \\ *Corresponding Author Email: zhangyang@jlict.edu.cn
}

This is an open access article distributed under the Creative Commons Attribution License, which permits unrestricted use, distribution, and reproduction in any medium, provided the original work is properly cited

\section{ARTICLE DETAILS}

\section{Article History:}

Received 26 June 2018 Accepted 2 july 2018

Available online 1 August 2018

\section{ABSTRACT}

Compound $\mathbf{0 - 1 9}$ is a promising prodrug candidate of 0-desmethylvenlafaxine (ODV) with excellent oral bioavailability and improved brain uptake. In present investigation, with the aim to gain the information on druggability of $\mathbf{0 - 1 9}$, the DSC analysis and physicochemical properties including solubility (S), lipid/water partition coefficient (Log P) coupled with solid state stability evaluation were performed and compared with ODV. Results indicated that 0-19 showed unique double peaks associated with the crystal transition during differential scanning calorimeter (DSC) processing as well as excellent stable properties during storage in room temperature. Its solubility and Log P exhibited similar trends towards ODV and mainly influenced by the countered $\mathrm{pH}$ environment. Herein, this work would be helpful for the further development of 0-19 as a novel antidepressant drug.

KEYWORDS

Compound 0-19, DSC analysis, solubility, Log P

\section{INTRODUCTION}

With the development of social economics, the pace of life and work is accelerating, more and more people have suffered from various kinds of central nervous system (CNS) diseases, among which depression is one of the most common neuropsychiatric disorders affecting approximately $20 \%$ of the population at any time during their lifetime [1]. The World Health Organization (WHO) estimated that depression will become the second leading cause of long-term disability in the world by the year2020, second only to ischemic heart disease $[2,3]$. Despite a wide range of the therapeutic drug options, however, like most CNS drugs, antidepressant medication is also subject to the problems of delayed onset and high variability [4-7].Thus, the search of enhancing drug delivery for optimizing the ideal antidepressant therapy remains an ongoing concern [8].

Venlafaxine (VEN) is a selective serotonin and norepinephrinere uptake inhibitor (SNRI) without blocking muscarinic acetylcholine, histaminergic and $\alpha 1$-adrenergic receptors, which was firstly marketed in US in 1994 for the treatment of major depressive disorder (MDD) $[9,10]$. After oral administration, VEN is well absorbed in gastrointestinal tract and metabolized by cytochrome P450 2D6 (CYP2D6) isoenzyme in liver to produce 0 -desmethylvenlafaxine (ODV), the major metabolite accounting for $56 \%$ of the total metabolites of VEN. ODV exerts similar antidepressant activity compared with VEN, and possesses a much longer half-life ranging from 9 to $13 \mathrm{~h}$ [11]. In addition, ODV is mainly metabolized by uridinediphosphate (UDP)-glucuronosyltransferases, not CYP2D6 isoenzyme, making it less prone to be affected by genetic polymorphism than that of VEN $[12,13]$. These favorable properties made ODV being marketed in US as a novel antidepressant in 2008, but unexpectedly, it failed to be approved in EU due to an unsatisfactory risk-benefit balance in both hot flushes and depression [14]. Moreover, the recommended minimum effective dose of ODV is up to $50 \mathrm{mg} /$ day, it may explain the efficacy deficiency found in some situations $[15,16]$. The bioavailability of ODV in humans is approximately $80 \%$, raising the question of whether its high-dose is caused by the low drug exposure in brain after oral administration. Therefore, in previous study, we designed and synthesized several lipophilic phenolic esters of ODV to enhance its blood-brain barrier (BBB) permeability. In pharmacokinetic evaluation, compound $1 \mathrm{n}(0-19)$, the piperonylic acid ester of ODV exhibited high capacity to improve the relative bioavailability of ODV both in rats and in dogs, as well as potentiating the brain uptake of ODV in rats, making it a promising prodrug candidate of ODV with elevated brain uptake [17].

In present investigation, the DSC analysis and physicochemical properties including solubility (S), lipid/water partition coefficient (Log P) coupled with solid state stability evaluation were performed to provide additional information for identification and formulation development of compound 0-19.

\section{MATERIALS}

4-(2-(dimethylamino)-1-(1-hydroxycyclohexyl)ethyl)phenol(ODV) was from Bide Pharmatech. Co. Ltd (HPLC Purity > 98\%, Shanghai, China). Other chemicals including, sodium hydroxide, potassium dihydrogen phosphate, disodium hydrogen phosphate were obtained from Civi Chemical Technology Co. Ltd. (Shanghai, China). Other solvents with analytical grade were purchased from Sino-pharm Chemical Reagent Co., Ltd. (Shanghai, China).

Differential scanning calorimeter (DSC) analysis was conducted by using a Mettler Toledo STAR® thermal analysis system, version 9.30 DSC $821 \circledast$ (Mettler-ToledoAG,Greifensee,Switzerland).Ultraviolet-Visible (UVVis) full wavelength scanning and absorbance determination were recorded by an UV-2550/UV-Vis Spectrophotometer (Shimadzu Corporation, Kyoto, Japan). 


\section{METHODS}

\subsection{DSC analysis}

The DSC analysis was conducted by using a Mettler Toledo STAR® thermal analysis system with nitrogen as protective gas $(100 \mathrm{ml} / \mathrm{min}-1)$ at a linear heating rate of $10^{\circ} \mathrm{C} \min -1$.The examinations were performed in the temperature interval $30-250^{\circ} \mathrm{C}$, the heating speed is $5 \mathrm{k} / \mathrm{min}$, and the sample mass range is $5-10 \mathrm{mg}$ [18].

The DSC parameters: temperature interval: $30-250^{\circ} \mathrm{C}$; heating rate: $10^{\circ} \mathrm{C} / \mathrm{min}$; amplitude: 0.5 or $1^{\circ} \mathrm{C}$; period: 0.5 or $1 \mathrm{~min}$.

\section{$3.2 \quad$ Equilibrium solubility}

\subsubsection{Full-field wavelength scanning}

The proper concentration of ODV and 0-19 solution was analyzed at the wavelength of 190-600 nm, respectively. It was found that ODV has the maximum absorption at $320 \mathrm{~nm}$, and the $0-19$ had the maximum absorption at $310 \mathrm{~nm}$.

\subsubsection{Preparation of standard solutions}

The concentrations of ODV and 0-19stock solutions were $10 \mathrm{~g} / \mathrm{mL}, 20$ $\mathrm{g} / \mathrm{mL}, 30 \mathrm{~g} / \mathrm{mL}, 40 \mathrm{~g} / \mathrm{mL}, 50 \mathrm{~g} / \mathrm{mL}, 60 \mathrm{~g} / \mathrm{mL}, 70 \mathrm{~g} / \mathrm{mL}, 80 \mathrm{~g} / \mathrm{mL}$, respectively, using methanol as solvents. The absorbance of ODV was measured at $320 \mathrm{~nm}$ and the absorbance of $0-19$ was measured at $310 \mathrm{~nm}$. With the mass concentration $(\mathrm{Y})$ as the longitudinal coordinate and the absorbance $(\mathrm{X})$ as the transverse coordinates, the standard curves were made respectively. The ODV regression equation was calculated to be $\mathrm{Y}=1.1621 \mathrm{X}-0.025, \mathrm{R} 2=0.9978$, and $0-19$ regression equation was $\mathrm{Y}$ $=0.0106 \mathrm{X}+0.0689, \mathrm{R} 2=0.9989$.

\subsubsection{Equilibrium solubility}

Two sets of five different gradients of phosphate buffer solution (PBS) with $\mathrm{pH}$ values of $2.0,5.0,6.8,7.4$, and 8.0 were prepared according to the method listed in Chinese Pharmacopoeia (2015 edition), and different $\mathrm{pH}$ gradient phosphate buffers were configured and adjusted with $\mathrm{NaOH}$. The PBS buffer solution was transferred to test tubes with volume of $10 \mathrm{~mL}$, and ODV and $0-19$ were sonicated at $37^{\circ} \mathrm{C}$ for $5 \mathrm{~min}$ to promoted is solution. The tubes were placed in a water bath thermostat and the temperature was maintained at $37 \pm 1^{\circ} \mathrm{C}$ for $12 \mathrm{~h}(130 \mathrm{r} / \mathrm{min})$. After centrifugation $\left(20^{\circ} \mathrm{C}, 4500 \mathrm{r} / \mathrm{min}, 20 \mathrm{~min}\right)$, the supernatant of the saturated solution was absorbed and filtered, after proper dilution, the absorbance was measured and the solubility was calculated [19].

\subsection{Lipid-water partition coefficient}

Lipid-water partition coefficient was determined according to the previously reported method with minor modifications. Prepare $50 \mathrm{~mL}$ of $0.5 \mathrm{mg} / \mathrm{mL}$ ODV-octanol solution and $0.5 \mathrm{mg} / \mathrm{mL} \mathrm{0-19-octanol} \mathrm{solution}$ with $100 \mathrm{~mL}$ of octanol solution saturated with water as the solvent. In both groups, accurately measure $5 \mathrm{~mL}$ of ODV-octanol and 0-19-octanol solution into test tubes, and accurately measure $5 \mathrm{~mL}$ of phosphate buffer with different $\mathrm{pH}$ gradients. Add into two groups of test tubes and place the test tubes in a water bath. In a constant-temperature shaker, the temperature was maintained at $37 \pm 1^{\circ} \mathrm{C}$ for 12 hours $(130 \mathrm{r} / \mathrm{min})$, centrifuged after standing $\left(20^{\circ} \mathrm{C}, 4500 \mathrm{r} / \mathrm{min}, 20 \mathrm{~min}\right)$ to make ODV and $\mathrm{O}-$ 19 fully dissolved in oil and water phases. The distribution was balanced. After standing, the upper oil phase solution and the lower aqueous phase solution were taken and filtered. After being properly diluted, the absorbance was measured and the lipid-water partition coefficient (P) was calculated as follows:

$\mathrm{P}=\mathrm{C} 0 / \mathrm{CW}$

Where $\mathrm{C} 0$ and $\mathrm{Cw}$ are the mass concentrations of ODV/0-19 in the oil and water phases, respectively.

\section{RESULTS AND DISCUSSION}

\subsection{DSC analysis}

DSC is an emerging technique for thermal analysis that has been widely used to measure the thermodynamic properties relating to transitions in materials as a function of temperature and time Modulated Differential Scanning Calorimetry (MDSC) is modification of conventional DSC that would provide more additional information for the compound of interest. Recently, MDSC has been used for the evaluation of drug stabilities [20]. As shown in Figure 5, The DSC curves of piperonylic acid(PA), ODV and O19 were obviously different, with an endothermic peak at $234.44^{\circ} \mathrm{C}$ for PA and an endothermic peak at $255.86^{\circ} \mathrm{C}$ for ODV. However, 0-19 exhibited an endothermic peak at $141.37^{\circ} \mathrm{C}$ followed by an endothermic peak at $163.31^{\circ} \mathrm{C}$, which might be due to the fact that the crystal transition of 0-19 could be carried out during the heating process.

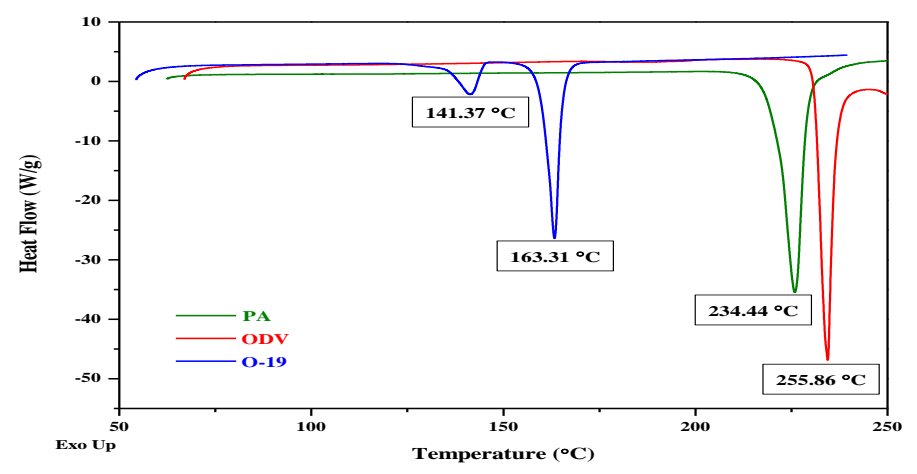

Figure 1: DSC thermograms for piperonylic acid (PA),ODV and 0-19.

To further prove the hypothesis, DSC analysis was performed on 0-19 stored for one month, two months and three months, respectively (Figure 6). There were still two endothermic peaks with similar peak value observed. It is speculated that the steady state crystal is formed by the metastable compound of 0-19.

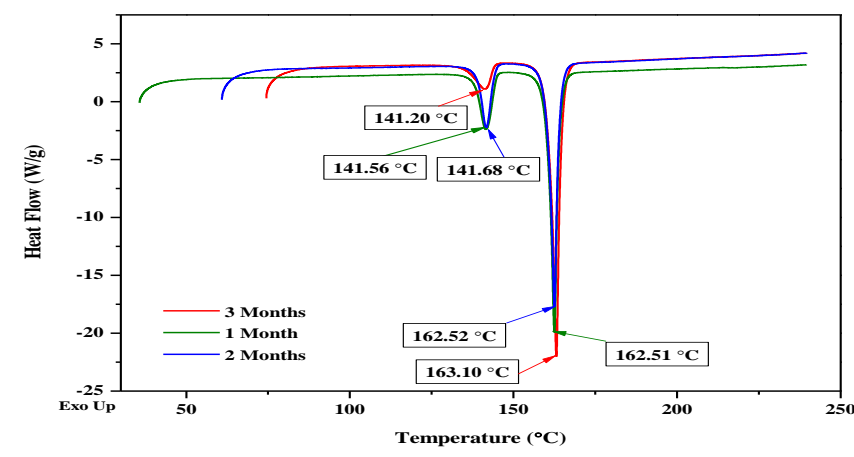

Figure 2: DSC thermograms for 0-19 stored for one month, two months and three months.

Therefore, in the production and processing processes, attention should be paid to controlling the temperature at about $141^{\circ} \mathrm{C}$ to avoid affecting the drug efficacy and safety due to crystal transformation. If the production and processing temperature is higher than $141^{\circ} \mathrm{C}$, it is necessary to separate the two crystal forms so as to avoid crystal transformation.

\subsection{Equilibrium solubility}

As shown in Figure 6 and 7, the solubility of ODV and 0-19 varies greatly under different $\mathrm{pH}$ conditions ranging from 2 to 9 , but the solubility of $\mathrm{O}$ 19 is far greater than that of ODV at different $\mathrm{pH}$ values. The solubilities of the two compound of interest were larger in the acidic condition, and ODV showed the maximum solubility $11.01 \mathrm{mg} / \mathrm{mL}$, while $0-19$ exhibited the maximum solubility $0.22 \mathrm{mg} / \mathrm{mL}$, when the $\mathrm{pH}$ value was 2 .As the $\mathrm{pH}$ increases, protons decrease and the hydroxyl groups in the solution increase, which would destroy the hydrogen bonds in the $\mathrm{N}-\mathrm{H}$, resulting in hydrophobicity. 


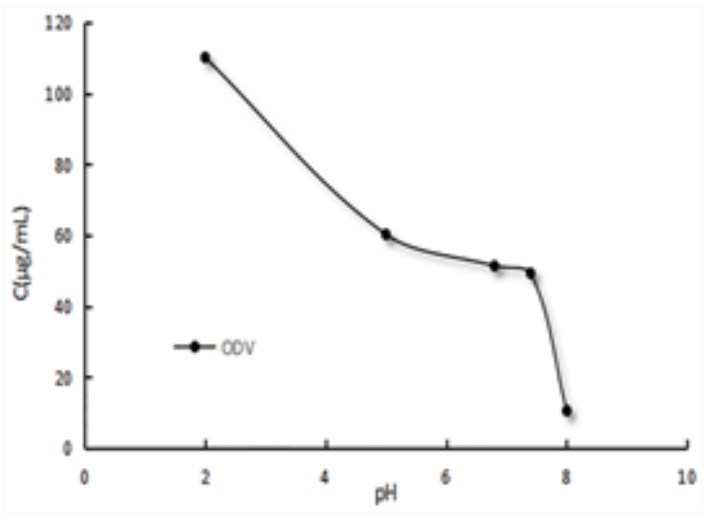

Figure 3: Solubility of ODV in different pH buffer solution.

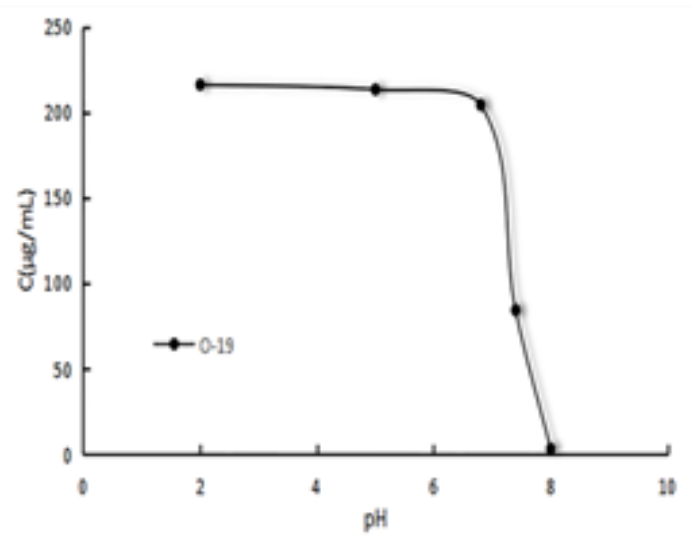

Figure 4: Solubility of 0-19 in different $\mathrm{pH}$ buffer solution.

According to the selected different $\mathrm{pH}$ conditions as much as possible to reflect the human gastrointestinal tract at different parts of the $\mathrm{pH}$, more accurately reflect the drug in the human gastrointestinal tract in different parts of the dissolution and penetration. Therefore, the increase in the $\mathrm{pH}$ value could reduce the solubilities of both ODV and 0-19, indicating that these two drugs might be more soluble in stomach than in intestinal tract.

\subsection{Lipid-water partition coefficient}

The lipid-water partition coefficient(P) is an important parameter in drug delivery systems. When the $\mathrm{P}$ value was $\operatorname{low}(\log \mathrm{P}<-2)$, excessive thermodynamic barrier would prevent the drug from penetrating through the lipid membrane; when the $\mathrm{P}$ value was high $(\log \mathrm{P}>3$ ), stronger lipophilicity will cause the drug to be difficult to pass from both sides of the membrane. Immobile water layer spreads. Therefore, in drug design, it should be considered whether it is within the optimal $P$ value $(-1<\log$ $\mathrm{P}<2$ ). From Figure 9 and 10, we can see that the Log $P$ value of ODV ranges from 0.12 to 0.95 , and the $\log P$ value of $0-19$ ranges from -0.02 to 1.37 , which all accorded with the ideal range from absorption, indicating that these two drugs might be well absorbed in human gastrointestinal tract. Although the lipid-water partition coefficient does not fully reflect the permeability of the drug in the body, it has some guidance for predicting the distribution of the drug in the body.

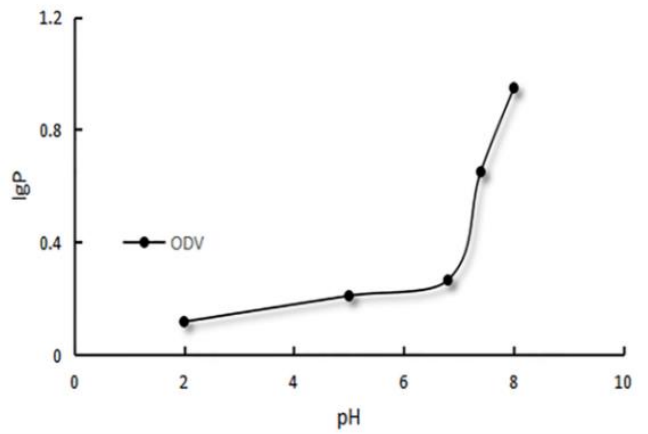

Figure 5: The Log $\mathrm{P}$ values of ODV in different $\mathrm{pH}$ buffers at $37^{\circ} \mathrm{C}$.

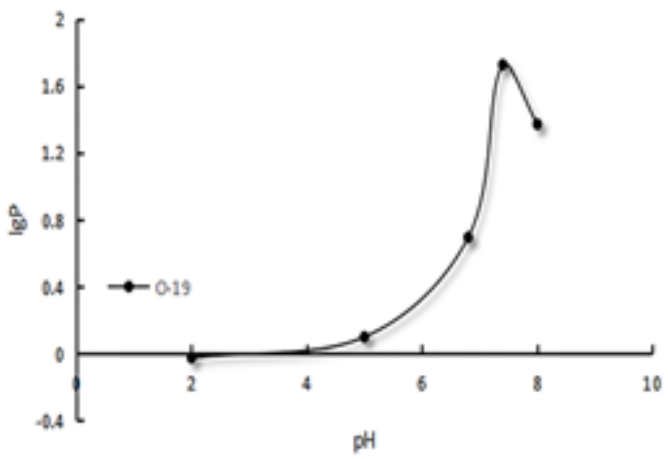

Figure 6: The Log P values ofO-19 in different $\mathrm{pH}$ buffers at $37^{\circ} \mathrm{C}$.

\section{CONCLUSION}

In summary, $0-19$, the newly synthesized prodrug of ODV has prominent properties for development. It has distinguished IR spectroscopic peaks compared with parent drug ODV and unique double peaks associated with the crystal transition during heating processing using DSC as well as excellent stable properties during storage. Its solubility and Log P showed similar trends towards ODV and mainly influenced by the countered $\mathrm{pH}$ environment, indicating that esterification does not alter its physical and chemical properties significantly. Its improved BBB permeability might be due to other mechanisms, such as transporter-mediated cross into the brain, which deserved to be explored further.

\section{ACKNOWLEDGMENTS}

This study was financed by the Key Scientific Foundation of Jilin Institute of Chemical Technology (Grant No. 2018003).

\section{REFERENCES}

[1] Musick, M.A., Wilson, J. 2003. Volunteering and depression: the role of psychological and social resources in different age groups. Social Science \& Medicine, 56 (2), 259-269.

[2] Ebrahim, S., Guyatt, G.H., Walter, S.D., Heelsansdell, D., Bellman, M., Hanna, S.E. 2013. Association of psychotherapy with disability benefit claim closure among patients disabled due to depression. Plos One, 8 (6), e67162.

[3] Mazaheri, M.A. 2012. Effect of educational intervention on general health and depression in temporary employees. International Journal of Preventive Medicine, 3 (7), 504.

[4] Rudorfer, M.V., Potter, W.Z. 1989. Antidepressants. Drugs, 37 (5), 713 738 .

[5] Spina, E., Perucca, E. 2016. Newer and older antidepressants: a comparative review of drug interactions. CNS Drugs, 2 (6), 479-497.

[6] Nabavi, S.M., Daglia, M., Braidy, N., Nabavi, S.F. 2015. Natural products, micronutrients, and nutraceuticals for the treatment of depression: a short review. Nutritional Neuroscience, 20 (3), 180-194.

[7] Richards, D. 2011. Prevalence and clinical course of depression: a review. Clinical Psychology Review, 31 (7), 1117-1125.

[8] Kilts, C.D. 2003. Potential new drug delivery systems for antidepressants: an overview. Journal of Clinical Psychiatry, 64 (18), 3133.

[9] Andrews, J.M., Ninan, P.T., Nemeroff, C.B. 1996. Venlafaxine: a novel antidepressant that has a dual mechanism of action. Depression, 4 (2), 48.

[10] Makhija, S.N., Vavia, P.R. 2002. Stability indicating LC method for the estimation of venlafaxine in pharmaceutical formulations. journal of pharmaceutical and biomedical analysis, 28 (6), 1055-1059.

[11] Ereshefsky, L., Pharm, D.B.C.P.P. Daniel, D.P.D. 2000. Review of the pharmacokinetics, pharmacogenetics, and drug interaction potential of antidepressants: Focus on venlafaxine[J]. Depression \& Anxiety, 12 (S1),30. 
[12] Perry, R., Cassagnol, M. 2009. Desvenlafaxine: a new serotoninnorepinephrine reuptake inhibitor for the treatment of adults with major depressive disorder. Clinical Therapeutics, 31 (1), 1374-1404.

[13] Listed, N. 2009. Desvenlafaxine: application withdrawal. desvenlafaxine: withdrawal of marketing application for depression also. Prescrire International, 18 (103), 197.

[14] Liebowitz, M.R., Tourian, K.A., Hwang, E., Mele, L. 2013. A doubleblind, randomized, placebo-controlled study assessing the efficacy and tolerability of desvenlafaxine 10 and $50 \mathrm{mg} /$ day in adult outpatients with major depressive disorder. BMC Psychiatry, 13 (1), 94.

[15] Iwata, N., Tourian, K.A., Hwang, E., Mele, L., Vialet, C. 2013. Efficacy and safety of desvenlafaxine 25 and $50 \mathrm{mg}$ /day in a randomized, placebocontrolled study of depressed outpatients. Journal of Psychiatric Practice, 19 (1), 5.

[16] Zhang, Y., Yang, Y., Zhao, S., Yang, Z., Yang, H., Fawcett, J. P. 2013. Phenolic esters of o-desmethylvenlafaxine with improved oral bioavailability and brain uptake. Molecules, 18 (12), 14920-34.

[17] Láng, P., Várkonyi, E., Ulrich, J., Szabórévész, P., Aigner, Z. 2015. Analysis of the polymorph changes of a drug candidate. Journal of Pharmaceutical \& Biomedical Analysis, 102, 229-235.
[18] Redasani, V.K., Bari, S.B. 2012. Synthesis and evaluation of mutual prodrugs of ibuprofen with menthol, thymol and eugenol. European Journal of Medicinal Chemistry, 56 (10), 134.

[19] Wu, Z., Patel, A., Dave, R., Yuan, X. 2010. Development of acetaminophen proline prodrug. Bioorganic \& Medicinal Chemistry Letters, 20 (13), 3851-3854.

[20] Qiao, J.W., Pei, G.Q., Liu, X.D., Rui-Qiang, S.U., Sun, Z.X., Zhi-Quan, Z. 2013. Determination of solubility and apparent oil/water partition coefficient of total flavonoids from scutellaria baicalensis georgi. Chinese Journal of Hospital Pharmacy, 33 (24), 2026-2028.

\section{ABOUT THE AUTHORS}

Zihao Zhang, postgraduate, research field: natural organic chemistry.

*Corresponding author: Yang Zhang*, graduate supervisor, research field: medicinal chemistry, E-mail: zhangyang@jlict.edu.cn

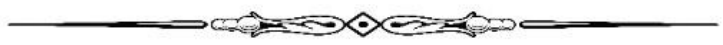

